Original research

\title{
Simulated electronic health documentation: A cross-sectional exploration of factors influencing nursing students' intention to use
}

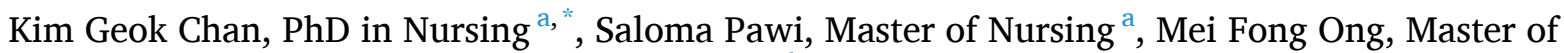 \\ Nursing ${ }^{a}$, Yanika Kowitlawakul, PhD in nursing ${ }^{\text {b }}$, Siew Ching Goy, PhD in Labour Economics ${ }^{\text {a, c }}$ \\ ${ }^{a}$ Faculty of Medicine and Health Sciences, Universiti Malaysia Sarawak, Sarawak, Malaysia \\ ${ }^{\mathrm{b}}$ National University of Singapore, Sarawak, Malaysia \\ ${ }^{\mathrm{c}}$ Faculty of Social Sciences and Humanities, Universiti Malaysia Sarawak
}

\section{A R T I C L E I N F O}

\section{Keywords:}

Electronic health documentation

Nursing students

Intention to use

Simulated

\begin{abstract}
A B S T R A C T
The aim of this study was to investigate factors influencing nursing students' intention to use a simulated webapplication 'Integrated Nursing Education System' for practicing electronic health documentation. The crosssectional study was conducted at a Malaysian University that provides undergraduate nursing degree program. A total of 133 undergraduate nursing students in their year 2 to year 4 of the program were recruited. They had accessed the simulated web-application as part of the teaching-learning activities during the academic year 2016/2017. Technology Acceptance Model was used to guide the study. Validated questionnaires were used to measure the students' perceived ease of use, perceived usefulness, attitudes and intention to use the application. Data collection was done at the end of the semester. Data analysis was done using SPSS (19.0) and AMOS (23.0). Perceived usefulness was the most influential factor of the students' intention to use the simulated webapplication. Perceived ease of use influenced their perceived usefulness significantly. Nurse educators should explain the usefulness of the simulated web-application before assigning students to access it to practice electronic health documentation. The availability of a stable internet access and IT support is important to influence students' perceived ease of use and intention to use the application.
\end{abstract}

\section{Introduction}

Electronic health record systems (EHRs) have been implemented in healthcare organizations in different countries in the last decade. EHRs have not been fully implemented throughout the Malaysian healthcare system, but implementation is progressing in selected hospitals and healthcare centers. The assumptions are that the adoption of EHRs would help to improve access to clinical information and patient data, improve inter-professional integration, patient safety, increase healthcare quality and reduce the healthcare costs (Bate, 2010; Bresnick, n. d; Cherry et al., 2011; Murphy, 2011). EHRs enable health information to be made available at all times for rapid transmission across different sites and disciplines within the health systems. It therefore improves healthcare services and the quality of patient care (Baillie et al., 2012; Cherry et al., 2017).

Healthcare professionals including nurses utilize EHRs in order to access health-related data such as patient history, physicians' orders and selected health documents. The health-related documents in the EHRs utilized by nurses would include, patient assessment, such as vital signs, fluid intake and output balance, nursing interventions, progress notes and incident reports.

In many instances the same data set of a patient in the EHRs is accessed by administrative personnel, physicians, nurses, pharmacists and laboratory staff in order to make decisions regarding the patient's healthcare. All personnel involved in the EHRs have a shared responsibility and accountability to maintain the security and integrity of the patient's record (Nugawela and Tony, 2011). EHRs have been used to ensure accuracy of patient documentation which includes prescription information. As a consequence, with the use of the EHRs technology, the necessity and dependency on hardcopy patient records has been reduced.

Bresnick (n.d) emphasizes that for health information technology (IT) to reduce patient-safety errors, health care providers must understand the role of health IT for patient safety. According to Bresnick (n.d),

\footnotetext{
* Corresponding author. Universiti Malaysia Sarawak, 94300 Kota Samarahan, Sarawak, Malaysia.

E-mail addresses: kgchan@unimas.my, kgchan@unimas.my (K.G. Chan), psaloma@unimas.my (S. Pawi), mfong@unimas.my (M.F. Ong), nuryk@nus.edu.sg (Y. Kowitlawakul), scgoy@unimas.my (S.C. Goy).
} 